\title{
Chronic ammonia exposure does not influence hepatic gene expression in growing pigs
}

\author{
Z. Cheng, E. A. O'Connor, Q. Jia, T. G. M. Demmers, C. M. Wathes and D. C. Wathes ${ }^{\dagger}$ \\ The Royal Veterinary College, Hawkshead Lane, Hatfield, Hertfordshire AL9 7 TA, UK
}

(Received 11 March 2013; Accepted 16 October 2013; First published online 27 November 2013)

\begin{abstract}
Housed pigs are often exposed to elevated concentrations of atmospheric ammonia. This aerial pollutant is widely considered to be an environmental stressor that also predisposes to reduced growth rates and poor health, although evidence to support this view is limited. Hepatic gene expression is very responsive to stress and metabolic effects. Two batches of growing pigs were therefore exposed to a nominal concentration of atmospheric ammonia of either 5 ppm (low) or 20 ppm (high) from 4 weeks of age for 15 weeks. Growth rates were monitored. Samples of liver were taken after slaughter (at 19 weeks of age). Samples from the second batch were analysed for global gene expression using $23 \mathrm{~K}$ Affymetrix GeneChip porcine genome arrays. Samples from both batches were subsequently tested for five candidate genes using quantitative real-time PCR (qPCR). The array analysis failed to detect any significant changes in hepatic gene expression following chronic exposure to atmospheric ammonia. Animals clustered into two main groups but this was not related to the experimental treatment. There was also no difference in growth rates between groups. The $q P C R$ analyses validated the array results by showing similar fold changes in gene expression to the arrays. They revealed a significant batch effect in expression of lipin 1 (LPIN1), Chemokine (C-X-C motif) ligand 14 (CXCL14), serine dehydratase (SDS) and hepcidin antimicrobial peptide (HAMP). Only CXCL14, a chemotactic cytokine for monocytes, was significantly down-regulated in response to ammonia. As chronic exposure to atmospheric ammonia did not have a clear influence on hepatic gene expression, this finding implies that 20 ppm of atmospheric ammonia did not pose a significant material risk to the health or metabolism of housed pigs.
\end{abstract}

Keywords: pigs, ammonia, liver, gene expression, chronic exposure

\section{Implications}

Some earlier research suggests that exposing pigs to high concentrations of atmospheric ammonia ( $\geqslant 20 \mathrm{ppm}$ ) compromises their health. However, this speculation has been based upon extremely brief, unrealistic exposures. Recently, we kept pigs at either $\sim 20$ ppm ammonia or in 'fresh' air for 15 weeks (i.e. an entire production cycle) but did not find any evidence of a change in liver function. This implies that pigs can be kept at $\sim 20 \mathrm{ppm}$ ammonia without affecting either their health or metabolism.

\section{Introduction}

Housed pigs are routinely exposed to atmospheric ammonia at concentrations that some have long considered are hazardous to their health and/or productivity (e.g. Drummond et al., 1980; Groot Koerkamp et al., 1998). Furthermore,

${ }^{\dagger}$ E-mail: dcwathes@rvc.ac.uk ammonia is considered a risk factor for the development of lung disease in humans, in particular agricultural workers and cleaners (Omland, 2002; Anderson et al., 2003; Vizcaya et al., 2011). Although some studies have found effects of elevated ammonia on growth and feed conversion efficiency in pigs, the experimental concentrations used often exceeded those found in commercial piggeries, sometimes excessively so (up to 150 ppm Stombaugh et al., 1969; Drummond et al., 1980). With respect to health, experiments have often failed to show changes in lung tissue or growth when pigs were co-exposed to both ammonia and an infectious agent (aerosols of Escherichia coli, toxigenic Pasteurella multocida or natural exposure to mycoplasma and bacteria; Drummond et al., 1978; Diekman et al., 1993). The long-standing belief that exposure to ammonia is harmful was tested recently in a large experiment involving about 1000 weaner pigs; it showed that exposure for $5 \frac{1}{2}$ weeks post-weaning to concentrations of atmospheric ammonia up to $\sim 40 \mathrm{ppm}$ had no effect on either productivity (Wathes et al., 2004) or respiratory disease (Done et al., 2005), although weaner pigs were shown to find 
concentrations $>20 \mathrm{ppm}$ aversive when given a choice of environments using preference testing (Jones et al., 1999). The former findings are counter-intuitive and imply that there is little reason for farmers or others to worry about atmospheric ammonia in terms of pig production, other than any concerns about the pig's preferences for fresh air.

Recently, we have studied the behavioural and physiological responses of growing pigs exposed continuously to atmospheric ammonia for 15 weeks (O'Connor et al., 2010; Parker et al., 2010). Here protracted, controlled exposure mimics environmental management in pig farming. Although there was evidence that the pigs found $20 \mathrm{ppm}$ of ammonia exposure stressful (they exhibited less play behaviour and appeared to have down-regulated hypothalamic-pituitary axes), there were few effects on important production parameters such as growth and food conversion efficiency as well as general health scores. The higher concentration of ammonia used in this experiment (nominally $20 \mathrm{ppm}$ ) is commercially relevant as the current occupational exposure standard in humans is $8 \mathrm{~h}$ of exposure to $25 \mathrm{ppm}$ ammonia in any $24 \mathrm{~h}$ period (Health and Safety Executive, 2011). This is often taken as a guideline for ammonia exposure of pigs and other housed livestock in the absence of evidence to the contrary: there is currently no legislation regarding maximum atmospheric ammonia in pig housing (Groot Koerkamp et al., 1998).

The liver is an organ, which has a central role in the regulation of carbohydrate, protein and lipid metabolism, immune function, inflammation, hormone metabolism and removal of waste products from the blood (Nemeth et al., 2009). Changes in circulating glucocorticoid levels and cytokines associated with stress and disease are known to influence hepatic function (Ingenbleek and Bernstein, 1999; Chida et al., 2006; Marelli et al., 2010). The liver therefore plays a sentinel role in detecting and responding to factors affecting normal homoeostasis. The aim of this experiment was to determine any changes in hepatic gene expression in growing pigs, which were chronically exposed to atmospheric ammonia at a nominal concentration of $20 \mathrm{ppm}$.

\section{Material and methods}

\section{Experimental design}

This work was regulated under the United Kingdom Animals (Scientific Procedures) Act 1986. Full details of the experiment can be found in O'Connor et al. (2010). Briefly, two batches $\left(N_{\text {batch }}=112\right)$ of 4 -week-old hybrid gilts $(50 \%$ White synthetic Pietrain - 25\% white Duroc, $12.5 \%$ Landrace, $12.5 \%$ Large White; PIC, Carlisle, Cumbria, UK) were obtained at weaning from the same commercial indoor pig farm. The first batch was obtained in May and the second in September 2008. On arrival, they were allocated randomly to groups of 14, kept in one of eight experimental rooms $\left(\sim 19.6 \mathrm{~m}^{2}\right)$ in a $2^{3}$ fully factorial design and maintained under a combination of either low (control) or high ammonia (nominally 5 or $20 \mathrm{ppm}$ of atmospheric ammonia; low or high mechanical noise (nominally $<60$ v. $80 \mathrm{~dB}(\mathrm{~A})$ ) and low or high light intensity (nominally 40 v. 200 lux for 12 h). Only liver samples from the pigs in the control or single-treatment ammonia rooms were used for the current study, so they were also exposed to control levels of light intensity and noise, that is, nominally 200 lux and $<60 \mathrm{~dB}(\mathrm{~A})$. Exposure to the environmental stressors began at the start of the experiment (i.e. on arrival of the pigs at the experimental site) and continued to its conclusion 15 weeks later. Growth parameters were monitored by manually weighing all the pigs once per week using calibrated scales (Pharmweigh Junior, Bury St Edmunds, Suffolk, UK). Health was monitored weekly with respect to nasal and/or ocular discharge, respiratory difficulty, diarrhoea and lameness as described previously (O'Connor et al., 2010).

The pigs were transported to a commercial abattoir at the end of the experiment for slaughter and removal of liver tissues. Small sections $\left(\sim 1 \mathrm{~cm}^{2}\right)$ of each liver were dissected, wrapped in foil, frozen in liquid nitrogen, transferred to prelabeled bags, transported back to the laboratory on dry ice and stored at $-80^{\circ} \mathrm{C}$ before RNA extraction.

\section{RNA extraction}

Total RNA was prepared from $100 \mathrm{mg}$ of fragmented frozen liver tissue of randomly selected pigs from one control room and one ammoniated room in each batch (eight pigs per treatment in Batch 1, seven per treatment in Batch 2, total $n=30$ ). Extraction of total RNA was carried out following an ARK Genomics Standard Operating Procedure (http://www. ark-genomics.org/protocols IGF100.00: Isolation of total RNA). A two-step extraction method was used, first with Trizol then with a RNeasy mini kit (QIAGEN 74104, Hilden, Germany) for further purification. RNA concentration and purity were determined using a NanoDrop ND-1000 spectrophotometer (NanoDrop Technologies Inc., Wilmington, $D E$, USA), where all samples had a 260/280 ratio of absorbance between 1.8 and 2.1. Samples from Batch $2(n=14)$ were used for microarray analysis followed by quantitative real-time PCR ( $q P C R$ ) on selected genes. Samples from Batch 1 were only used for qPCR.

\section{Microarray hybridisation}

All total RNA samples were checked for the concentration, integrity and purity using an Agilent Bioanalyzer according to the manufacturer's instructions (Agilent Technologies Inc., Santa Clara, CA, USA). Microarray hybridisation and data acquisition were carried out by ARK-Genomics (Roslin Institute, University of Edinburgh) using $23 \mathrm{~K}$ Affymetrix GeneChip Porcine Genome Arrays based on established ARK-Genomics protocols (http://www.ark-genomics.org/protocols).

\section{Microarray data analysis}

Data were analysed using an $S+$ ArrayAnalyzer 2.1 built in S-Plus Enterprise Developer 7.0 software package (Insightful Corp., Seattle, Washington, USA). Probe-level expression data generated by the scanner (.CEL files) were imported into the $S+$ ArrayAnalyzer. Each probe set on the Affymetrix array contains 11 pairs of primers to target one gene: as an 
initial quality control step any probes with readings for less than seven detected pairs were filtered out. Quality control diagnostics were performed using plots of MvA, Box, RNA degradation and principal component analysis for expression intensity, which confirmed the good quality of all slides. The probe pairs were summarised into a single value per gene using Robust Multichip Analysis and normalised with a median inter-quartile range method.

Principle component analysis of the array data was performed using the BioConductor 2.4 in R-Package. Differences of probes/genes expression between control and ammoniatreated groups were compared using an unpaired $t$-test with Benjamini-Hochberg adjustment for a false discovery rate (FDR). In addition, differences of the normalised expression values between treatment groups were tested using a Significant Analysis of Microarray package (SAM, Stanford University, USA) at a FDR rate of $\alpha=0.05$.

\section{$q P C R$}

Four of the most highly down-regulated genes were selected for follow-up studies by qPCR: lipin 1 (LPIN1), Chemokine (C-X-C motif) ligand 14 (CXCL14), serine dehydratase (SDS) and hepcidin antimicrobial peptide (HAMP) plus actin beta ( $A C T B$; as a reference gene; see Table 1 for details). These genes were chosen based on the functional information available at the time for the pig genome, suggesting that they might play a role in metabolism and diseases affecting liver. All chemicals and reagents were purchased from Sigma-Aldrich Company Ltd. (Poole, Dorset, UK) or VWR International Ltd. (Poole, Dorset, UK) unless otherwise specified. Optimised qPCR assays were developed, as described previously (Fenwick et al., 2008). Total RNA from each sample was treated for potential genomic DNA carryover in a single reaction in accordance with guidelines supplied by Promega (Promega Corporation, Madison, WI, USA). From this reaction, precisely $1 \mu \mathrm{g}$ of DNase-treated RNA was reverse transcribed using random hexamer primers and processed accordingly (Reverse Transcription System Kit; Promega). A mastermix of reagents was prepared for the above reaction to minimise potential variation. $A$ negative control included all reagents as above, minus the CDNA template. Gene symbols, sequence information, accession numbers and expected product lengths are provided in Supplementary Table S1.

Gene transcripts were quantified as described in detail previously (Fenwick et al., 2008). Standards for qPCR were prepared from purified PCR products that were quantified by spectroscopy (NanoDrop) and diluted over at least eight orders of magnitude. Briefly, for each assay a mastermix was prepared that contained a final concentration of $10 \mu \mathrm{l} \mathrm{Kapa}$ qPCR SYBR Green Mix (Anachem Ltd, Luton, UK), 500 nM forward and reverse primers and nuclease-free water. Primer annealing and amplicon-specific melting temperatures were determined using the gradient function of CFX-96 Real-time PCR detection system (Bio-Rad Laboratories, Hercules, CA. USA). Equivalent amounts of sample cDNA were added to each reaction in duplicate. To minimise variation, all samples included in each analysis were derived from the same reverse transcription (RT) batch, prepared under the same conditions and were analysed on a single plate. Thermal cycling conditions applied to each assay consisted of an initial Taq activation step at $95^{\circ} \mathrm{C}$ for $15 \mathrm{~min}$ followed by 38 cycles of denaturation $\left(95^{\circ} \mathrm{C}\right.$ ), annealing (range $50.0^{\circ} \mathrm{C}$ to $64.2^{\circ} \mathrm{C}$, see Supplementary Table $\mathrm{S} 1$ ), extension $\left(72^{\circ} \mathrm{C}\right)$ and an ampliconspecific fluorescence acquisition reading (range $74^{\circ} \mathrm{C}$ to $84^{\circ} \mathrm{C}$ ). A melting curve analysis was performed for each amplicon between $50^{\circ} \mathrm{C}$ and $95^{\circ} \mathrm{C}$ and as such any smaller non-specific products such as dimers were melted (if present) before fluorescence acquisition. All qPCR results were recorded with the Bio-Rad CFX Manager Software (V1.6, Bio-Rad Laboratories). For comparison of expression data, absolute values were derived from standard curves generated from purified CDNAs identical to amplified products and expressed as $\mathrm{fg} / \mathrm{\mu g}$ reverse-transcribed RNA.

\section{Data analysis}

Data from the $\mathrm{gPCR}$ analysis were expressed as the mean and root mean square error in $\mathrm{fg} / 1 \mu \mathrm{g}$ RNA and subjected to ANOVA using SPSS V19 software package (Chicago, IL, USA), including treatment (Control or High Ammonia) and Batch (1 or 2) as factors. Fold changes between groups were calculated as Ammonia/Control when the value of the ammonia group was greater than that of control group and as - Control/Ammonia when the value of ammonia group was less than that of control group using the values without logarithmic transform. Differences were considered significant at $P<0.05$.

\section{Results}

\section{Array analysis}

Out of $23 \mathrm{~K}$ probes/genes included on the array, around $15 \mathrm{~K}$ currently have gene symbol annotations. Overall, only 21 of these genes were down-regulated $>1.5$ fold and nine were up-regulated $>1.5$ fold in the $20 \mathrm{ppm}$ ammonia-treated group in comparison with the controls The fold changes for the top 8 genes in each direction are shown in Table 1. Samples from all 14 pigs were analysed using principal component analysis. This identified two groups of animals, but pigs from the control and high ammonia treatments were equally divided between the two groups (Figure 1). Differences of probes/genes expression between control and ammonia-treated groups were next compared using standard array analysis methods: (i) an unpaired $t$-test with Benjamini-Hochberg adjustment for FDR; and (ii) normalised expression values between treatment groups were tested using SAM at an FDR rate of $\alpha=0.05$. Neither method detected significant differential expression of hepatic genes between treatment groups.

\section{$q P C R$}

Five genes were selected for follow-up studies by qPCR to validate the array results: ACTB (reference gene), LPIN1, 
Cheng, O'Connor, Jia, Demmers, Wathes and Wathes

Table 1 Top eight hepatic genes up- or down-regulated after 15 weeks exposure of growing pigs to atmospheric ammonia (either $<5$ ppm (control) or $\sim 20 \mathrm{ppm}$ ) according to fold changes in expression

\begin{tabular}{|c|c|c|c|}
\hline Gene symbol & Gene name & Fold change & Brief description of function \\
\hline \multicolumn{4}{|l|}{ Down-requlated } \\
\hline$H A M P^{a}$ & Hepcidin antimicrobial peptide & -3.24 & Iron homoeostasis, antimicrobial activity \\
\hline CYP3A22 & Cytochrome P450, subfamily IIIA, polypeptide 22 & -2.06 & Metabolism of steroids and drugs \\
\hline$S D S^{a}$ & Serine dehydratase & -2.0 & $\begin{array}{l}\text { Metabolism including conversion of L-serine to } \\
\text { pyruvate and ammonia }\end{array}$ \\
\hline LPIN1 ${ }^{a}$ & Lipin 1 & -1.94 & Triglyceride synthesis \\
\hline LOC100513945 & $\begin{array}{l}\text { Enoyl-CoA hydratase domain-containing protein } 3 \text {, } \\
\text { mitochondrial-like }\end{array}$ & -1.89 & Not known \\
\hline$C X C L 14^{a}$ & Chemokine (C-X-C motif) ligand 14 & -1.82 & Cytokine, monocyte chemotaxis \\
\hline$D D O$ & D-aspartate oxidase & -1.75 & $\begin{array}{l}\text { Oxidative deamination of D-aspartate and } \\
\mathrm{N} \text {-methyl-D-aspartate }\end{array}$ \\
\hline IGFBP1 & Insulin-like growth factor binding protein 1 & -1.66 & Modulation of IGF bioactivity \\
\hline \multicolumn{4}{|l|}{ Up-regulated } \\
\hline LOC100153368 & Similar to elongation of very long fatty acids-like 2 & +3.05 & Fatty acid synthesis \\
\hline F13A1 & F13A1 coagulation factor XIII, A1 polypeptide & +2.29 & Blood clotting \\
\hline ZNF133 & Zinc finger protein 133 & +1.84 & Transcription factor \\
\hline LOC100515931 & Protein phosphatase 1 regulatory subunit 3B-like & +1.72 & Putative role in glycogen synthesis \\
\hline NPG1 & Protegrin 1 & +1.68 & Antimicrobial \\
\hline CLDN1 & Claudin 1 & +1.59 & Component of tight junctions \\
\hline PROM1 & Prominin 1 & +1.54 & Pentaspan transmembrane glycoprotein \\
\hline ALAS1 & Aminolevulinate, delta-, synthase 1 & +1.54 & Haeme biosynthesis \\
\hline
\end{tabular}

aUsed in follow-up study by qPCR.

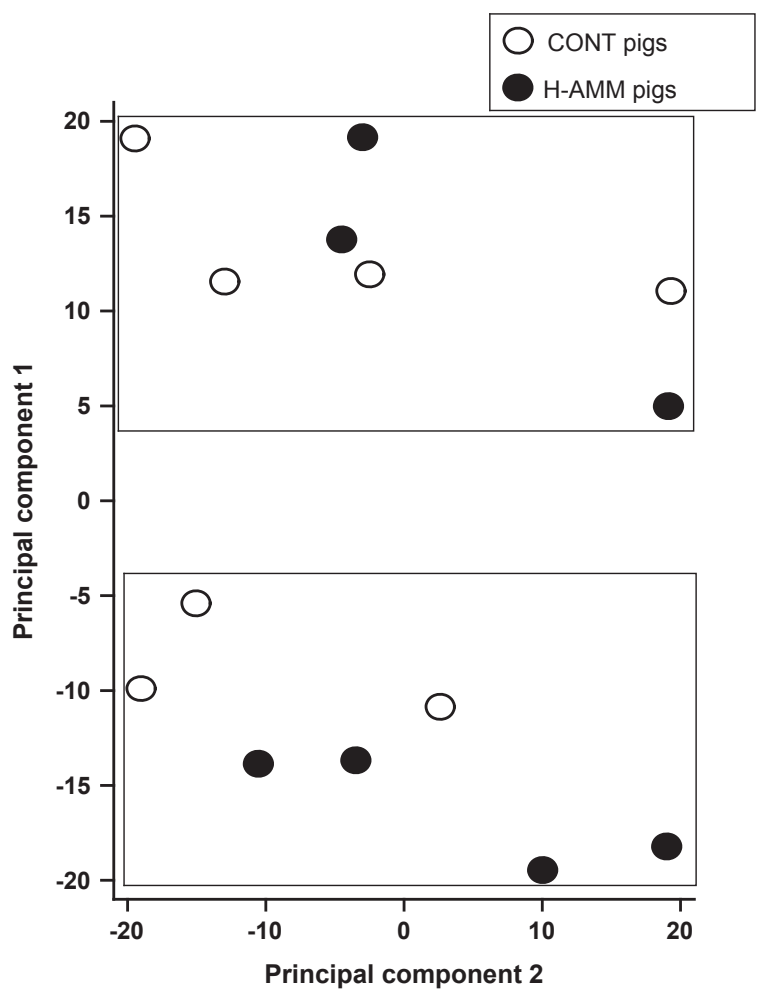

Figure 1 Principal component analysis of hepatic samples from growing pigs exposed to either nominally $5 \mathrm{ppm}$ (CONT) or $20 \mathrm{ppm}$ ammonia (H-AMM), $n=7$ pigs per treatment. Affymetrix GeneChip porcine arrays. Samples were analysed by $23 \mathrm{~K}$ Affymetrix porcine arrays. Two clusters were identified but they did not relate to the treatment.
CXCL14, SDS and HAMP. The samples from pigs in Batch 2 from the array analysis were repeated and eight additional pigs from each of the control and ammonia-treated groups in Batch 1 were also included. Results are summarised in Table 2. This showed good agreement in the fold changes in expression detected by array and $\mathrm{QPCR}$ analysis in Batch 2 but these fold change results were not consistent with those found using qPCR in Batch 1. ANOVA indicted that batch had a significant influence on expression of all of these genes at $P \leqslant 0.01$ but only one (CXCL14) was significantly influenced by ammonia treatment $(P=0.002)$. The reference gene $A C T B$ was not altered in response to treatment. As a further check on the data, the expression of the four test genes was calculated as the ratio of expression to ACTB. Using this approach, there were no significant differences in expression according to treatment $(P$ all $>0.1)$.

\section{Weight and growth rates}

Data on weights of animals and growth rates have previously been reported for the complete experiment covering 224 pigs (O'Connor et al., 2010). In summary, the mean weight of the pigs increased from $7.8 \pm 0.1 \mathrm{~kg}$ in 4-week-old pigs at the start of the experiment to $81.9 \pm 0.7 \mathrm{~kg}$ in the 19-week-old pigs at the end of the experiment. There was a significant difference between batches in the mean weight over the course of the experiment: Batch 1, 36.0 $\pm 0.2 \mathrm{~kg}$; Batch 2 $39.3 \pm 0.2 \mathrm{~kg},(P<0.01)$. When batch was controlled for there was, however, no significant effect of any of the 
Hepatic response to atmospheric ammonia in pigs

Table 2 Hepatic gene expression measured by qPCR in the growing pig after 15 weeks exposure to atmospheric ammonia (either $<5$ ppm (control) or 20 ppm of atmospheric ammonia)

\begin{tabular}{|c|c|c|c|c|c|c|}
\hline & \multirow[b]{2}{*}{ Batch } & \multicolumn{5}{|c|}{ Gene $^{a}$} \\
\hline & & ACTB & LPIN1 & CXCL14 & SDS & HAMP \\
\hline Control $^{b}$ & 1 & 490 & 24 & 3.9 & 2.3 & 38 \\
\hline High ammonia ${ }^{b}$ & 1 & 501 & 21 & 2.6 & 2.5 & 37 \\
\hline RMSE & 1 & 348.4 & 11.4 & 2.3 & 1.8 & 32.1 \\
\hline Fold change $\mathrm{qPCR}$ & 1 & 1.02 & -1.14 & -1.51 & 1.11 & 1.02 \\
\hline Control $^{b}$ & 2 & 1650 & 126 & 9.4 & 24 & 315 \\
\hline High ammonia ${ }^{b}$ & 2 & 1220 & 59 & 4.5 & 13 & 152 \\
\hline RMSE & 2 & 548.3 & 68.3 & 2.7 & 13.8 & 235.8 \\
\hline Fold change $\mathrm{qPCR}$ & 2 & -1.35 & -2.14 & -2.09 & -1.79 & -2.06 \\
\hline Treatment $P$ & $1+2$ & 0.22 & 0.054 & 0.002 & 0.16 & 0.18 \\
\hline Batch $P$ & $1+2$ & $<0.001$ & $<0.001$ & $<0.001$ & $<0.001$ & 0.003 \\
\hline Treatment $\times$ Batch $P$ & $1+2$ & 0.19 & 0.076 & 0.057 & 0.138 & 0.186 \\
\hline Fold change array & 2 & -1.4 & -1.94 & -1.82 & -2.03 & -3.24 \\
\hline
\end{tabular}

RMSE = root mean square error; $q P C R=$ quantitative real-time $P C R$.

Gene expression was analysed using both $\mathrm{QPCR}$ and gene expression array.

${ }^{a}$ Genes analysed were: $A C T B=$ actin beta; $L P I N 1=$ lipin 1; $C X C L 14=$ Chemokine $(C-X-C$ motif) ligand 14; SDS= serine dehydratase; HAMP=hepcidin antimicrobial peptide.

Values shown are the means of eight pigs per group in Batch 1 and seven pigs per group in Batch 2 expressed in $\mathrm{fg} / \mu \mathrm{g} R \mathrm{RN} \times 10^{6}$.

Table 3 Comparison of weights and growth rates between growing pigs kept for 15 weeks in either control $(<5 \mathrm{ppm})$ or high ammonia ( 20 ppm) atmosphere

\begin{tabular}{lcccc}
\hline \hline Treatment & $n$ & $\begin{array}{c}\text { Initial weight }(\mathrm{kg}) \\
\text { at 4 } \text { weeks of age }\end{array}$ & $\begin{array}{c}\text { Final weight }(\mathrm{kg}) \\
\text { at 19 weeks of age }\end{array}$ & $\begin{array}{c}\text { Growth rate } \\
(\mathrm{kg} / \mathrm{day})\end{array}$ \\
\hline Control & 28 & $8.0 \pm 0.2$ & $80.6 \pm 1.1$ & $0.8 \pm 0.1$ \\
Ammonia & 28 & $8.0 \pm 0.2$ & $80.8 \pm 1.1$ & $0.8 \pm 0.1$ \\
RMSE & & 1.6 & 8.1 & 0.3 \\
$P$-value & 0.89 & 0.88 & 0.89 \\
\hline \hline
\end{tabular}

RMSE $=$ root mean square error.

Values are expressed as mean \pm s.e.m.

treatments on the mean weight or growth trajectories of the pigs. The average data for the animals in the control and ammonia-treated groups are summarised in Table 3.

\section{Discussion}

The results of this study showed little or no significant hepatic response of growing pigs after 15 weeks of exposure to $20 \mathrm{ppm}$ of atmospheric ammonia. Using standard analytical methods for gene expression arrays, there were no significant changes in expression. This was surprising for two reasons. First, array studies are able to detect small changes in gene expression across the whole genome. The experiment's design meant that it was able to detect a fold change of 1.25 between two samples, at $\alpha=0.05$ and a power $>0.8$ in a test of the experimental hypothesis with an unpaired $t$-test and making the usual assumptions about heteroscedastcity, random allocation of experimental subjects, etc.
Our results showed an extremely good relationship between the fold changes in gene expression measured by the arrays and $\mathrm{GPCR}$. This provides further confidence in the validity of the results.

Second, the liver is a central organ, which responds to stress, metabolic changes and disease, all of which might reasonably have been expected to change in response to the ammonia treatment (Berczi, 1998; Chida et al., 2006). The biological functions of the liver include detoxification of harmful substances in the blood, glycogen storage, protein synthesis, bile secretion and hormone synthesis (Nemeth et al., 2009). In the context of this experiment, it is unlikely that uptake of the atmospheric ammonia would have been sufficient to produce any measurable change in plasma ammonium levels. Instead it might have caused lung disease (Done et al., 2005) or caused the animals stress through living in an environment which they could find aversive (Jones et al., 1999). Using array analysis, we have previously detected many significant changes in hepatic gene expression in response to negative energy balance in cows (McCarthy et al., 2010) and transport stress in broiler chickens (Sherlock et al., 2012). Similarly, lesions of the foot and hock induced by ammonia treatment of the litter resulted in differential expression of 417 hepatic genes in broiler chickens (Sherlock et al., 2012). Others have successfully used expression profiling to monitor responses to calorie restriction in prepubertal pigs (Lkhagvadorj et al., 2010). Therefore, the lack of differentially expressed genes in liver of pigs exposed to ammonia suggests that a myriad of metabolic processes were apparently unaffected by this treatment.

The pigs used in this experiment were part of a larger study into the effects of three environmental stressors (ammonia, noise and low light). This found no significant 
difference in the overall activity levels or growth rates of pigs housed in either high-ammoniated or low-ammoniated environments, although, in common with the results on gene expression reported here, there was a significant batch effect (O'Connor et al., 2010; Parker et al., 2010). In particular, the mean weight of the pigs over the course of the experiment was higher in Batch 2, although both sets of animals came from the same source and genetic stock and were housed in the same building. After controlling for the batch effect, the pigs in the ammoniated rooms had slightly lower salivary cortisol, larger adrenal cortices and performed less play in week 3 of the experiment, although there were no differences in play behaviour in weeks 8 or 14 . As liver samples were only collected at the end of the experiment, it remains possible that changes in hepatic gene expression may have occurred earlier but that the pigs adapted to cope with this environment over time. However, we were interested in chronic not acute changes and from both a commercial and welfare perspective the net effect, integrated over an animal's lifetime, may be more important.

We selected four genes in addition to the reference gene $A C T B$ for further analysis, which showed slightly lower hepatic expression in the ammonia-treated pigs: SDS, LPIN1, $H A M P$ and $C X C L 14$. Although their changes in expression were not statistically significant, the functions of the proteins derived from these genes suggested that they might plausibly have been influenced by the treatment. Serine dehydratase is one of three enzymes involved in metabolising serine and glycine. The protein is found mainly in liver where L-serine dehydratase converts L-serine to pyruvate and ammonia (Ogawa, 2000). Lipin 1 is involved in adipose tissue development and triglyceride metabolism (Reue and Brindley, 2008). In humans, LPIN1 is a candidate gene for lipodystrophy, a disease that is characterised by loss of body fat, fatty liver, hypertriglyceridemia and insulin resistance. $H A M P$ is produced by the liver and plays an important role in the maintenance of iron homoeostasis. The gene is up-regulated during inflammation, potentially resulting in anaemia (Deicher and Hörl, 2006). Chemokine (C-X-C motif) ligand 14 is an immunoregulatory cytokine, which displays chemotactic activity for monocytes (Shurin et al., 2005).

Out of these genes, only CXCL14 showed a significant effect of ammonia treatment across both batches of pigs $(P<0.001)$, although there was also a trend $(P<0.054)$ for LPIN1. There has been limited previous work investigating hepatic CXCL14 expression using murine models. It is upregulated in response to hepatic injury (De Minicis et al., 2007; Li et al., 2011) and schistosome infection (Burke et al., 2010) and is thought to attract monocytes, promote fat deposition, inhibit hepatocyte proliferation and contribute to the formation of hepatic granulomas and fibrosis. Hepatic down-regulation, as seen here in response to atmospheric ammonia, would presumably decrease such responses, although the relevance of this observation is uncertain without further investigation.

Overall, our results did not support the hypothesis that chronic exposure to ammonia would be reflected in changes in hepatic gene expression. This suggests that growing pigs can adapt to this level of environmental exposure without affecting their production efficiency or health. Such levels of ammonia do, however, raise cause for concern with regard to welfare as pigs are known to find them aversive (Jones et al., 1999).

\section{Conclusions}

Despite traditional beliefs about the putative effects of exposure to atmospheric ammonia on the livestock performance, this experiment has not provided any scientific evidence that chronic exposure to a nominal concentration of $20 \mathrm{ppm}$ affects hepatic gene expression in growing pigs. Other studies of respiratory disease have also failed to find an effect.

\section{Acknowledgements}

This work was funded by the BBSRC. The authors thank members of the Centre for Animal Welfare, RVC for assistance with tissue collection at the abattoir. They are also grateful to staff at the RVC Biological Services Unit for animal husbandry.

\section{Supplementary material}

To view supplementary material for this article, please visit http://dx.doi.org/10.1017/S1751731113002127

\section{References}

Anderson N, Strader R and Davidson C 2003. Airborne reduced nitrogen: ammonia emissions from agriculture and other sources. Environment International 29, 277-286.

Berczi I 1998. The stress concept and neuroimmunoregulation in modern biology. Annals of the New York Academy of Science 851, 3-12.

Burke ML, McManus DP, Ramm GA, Duke M, Li Y, Jones MK and Gobert GN 2010. Temporal expression of chemokines dictates the hepatic inflammatory infiltrate in a murine model of schistosomiasis. Plos Neglected Tropical Diseases 4, e598.

Chida Y, Sudo N and Kubo C 2006. Does stress exacerbate liver diseases? Journal of Gastroenterology and Hepatology 21, 202-208.

De Minicis S, Sekim E, Uchinami H, Kluwe JN, Zhang C, Brenner $Y$ and Schwabesv RF 2007. Gene expression profiles during hepatic stellate cell activation in culture and in vivo. Gastroenterology 132, 1937-1946.

Deicher R and Hörl WH 2006. New insights into the regulation of iron homeostasis. European Journal of Clinical Investigation 36, 301-309.

Diekman MA, Scheidt AB, Suttonn AL, Green ML, Clapper JA, Kelly DT and Van Alstine WG 1993. Growth and reproductive performance, during exposure to ammonia, of gilts afflicted with pneumonia and atrophic rhinitis. American Journal of Veterinary Research 54, 2128-2131.

Done SH, Chennells DJ, Gresham ACJ, Williamson S, Hunt B, Taylor LL, Bland V, Jones P, Armstrong D, White RP, Demmers TGM, Teer N and Wathes CM 2005. Clinical and pathological responses of weaned pigs to atmospheric ammonia and dust. The Veterinary Record 157, 1571-1580.

Drummond JG, Curtis SE and Simon J 1978. Effects of atmospheric ammonia on pulmonary bacterial clearance in the young pig. American Journal of Veterinary Research 39, 211-212.

Drummond JG, Curtis SE, Simon J and Norton HW 1980. Effects of aerial ammonia on growth and health of young pigs. Journal of Animal Science 50, 1085-1091. 
Fenwick MA, Fitzpatrick M, Kenny DK, Diskin R, Patton J, Murphy JJ and Wathes DC 2008. Interrelationships between negative energy balance (NEB) and IGF regulation in liver of lactating cows. Domestic Animal Endocrinology 34, 31-44.

Groot Koerkamp PWG, Metz JHM, Uenk GH, Phillips VR, Holden MR, Sneath RW, Short JL, White RP, Hartung J, Seedorf J, Schröder M, Linkert KH, Pedersen S, Takai $\mathrm{H}$, Johnsen JO and Wathes CM 1998. Concentrations and emissions of ammonia in livestock buildings in Northern Europe. Journal of Agricultural Engineering Research 70, 79-95.

Health and Safety Executive 2011. EH40/2005 Workplace exposure limits, 2nd edition. HSE Books, London.

Ingenbleek $Y$ and Bernstein L 1999. The stressful condition as a nutritionally dependent adaptive dichotomy. Nutrition 15, 305-320.

Jones JB, Webster AJF and Wathes CM 1999. Trade-off between ammonia exposure and thermal comfort in pigs and the influence of social contact. Animal Science 68, 387-398.

Li J, Gao J, Yan D, Yuan Y, Sah S, Satya U, Liu M, Han W and Yu Y 2011. Neutralization of chemokine CXCL14 (BRAK) expression reduces $\mathrm{CCl} 4$ induced liver injury and steatosis in mice. European Journal of Pharmacology 671, 120-127.

Lkhagvadorj S, Qu L, Cai W, Couture OP, Barb CR, Hausman GJ, Nettleton D, Anderson LL, Dekkers JCM and Tuggle CK 2010. Gene expression profiling of the short-term adaptive response to acute caloric restriction in liver and adipose tissues of pigs differing in feed efficiency. American Journal of Physiology Regulatory Integrative and Comparative Physiology 298, R494-R507.

Marelli SP, Terova G, Cozzi MC, Lasagna E, Sarti FM and Cavalchini LG 2010. Gene expression of hepatic glucocorticoid receptor NR3C1 and correlation with plasmatic corticosterone in Italian chickens. Animal Biotechnology 21, 140-148.

McCarthy SD, Waters SM, Kenny DA, Diskin MG, Fitzpatrick R, Patton J Wathes DC and Morris DG 2010. Negative energy balance and hepatic gene expression patterns in high-yielding dairy cows during the early postpartum period: a global approach. Physiological Genomics 42A, 188-199.

Nemeth E, Baird AW and O'Farrelly C 2009. Microanatomy of the liver immune system. Seminars in Immunopathology 31, 333-343.

O'Connor EA, Parker MO, McLeman MA, Demmers TGM, Lowe JC, Cui L, Davey EL, Owen RC, Wathes CM and Abeyesinghe SM 2010. The impact of chronic environmental stressors on growing pigs, Sus scofra: 1. Stress physiology, production and play behaviour. Animal 4, 1899-1909.

Ogawa $\mathrm{H} 2000$. Structure and function relationships of serine dehydratases from various sources. Trends in Comparative Biochemistry and Physiology 6, 1-19.

Omland $\varnothing 2002$. Exposure and respiratory health in farming in temperate zones - a review of the literature. Annals of Agricultural and Environmental Medicine 9, 119-136.

Parker MO, O'Connor EA, McLeman MA, Demmers TGM, Lowe JC, Owen RC, Davey EL, Wathes CM and Abeyesinghe SM 2010. The impact of environmental stressors on growing pigs, Sus Scofra: 2. Social behaviour. Animal 4, 1910-1921. Reue K and Brindley DN 2008. Thematic review series: glycerolipids. Multiple roles for lipins/phosphatidate phosphatase enzymes in lipid metabolism. Journal of Lipid Research 49, 2493-2503.

Sherlock L, Wathes CM, Cheng Z and Wathes DC 2012. Differential hepatic gene expression in the broiler chicken in response to the combined stressors of catching, transport and slaughter at the end of production. Stress 15, 293-305.

Sherlock L, McKeegan DEF, Cheng Z, Wathes CM and Wathes DC 2012. Effects of contact dermatitis on hepatic gene expression in broilers. British Poultry Science 53, 439-452.

Shurin GV, Ferris R, Tourkova IL, Perez L, Lokshin A, Balkir L, Collins B, Chatta GS and Shurin MR 2005. Loss of new chemokine CXCL14 in tumor tissue is associated with low infiltration by dendritic cells (DC), while restoration of human CXCL14 expression in tumor cells causes attraction of DC both in vitro and in vivo. Journal of Immunology 174, 5490-5498.

Stombaugh DP, Teague HS and Roller WL 1969. Effects of atmospheric ammonia on the pig. Journal of Animal Science 28, 844-847.

Vizcaya D, Mirabelli MC, Antó JM, Orriols R, Burgos F, Arjona L and Zock JP 2011. A workforce-based study of occupational exposures and asthma symptoms in cleaning workers. Occupational and Environmental Medicine 68, 914-919.

Wathes CM, Demmers TGM, Teer N, White RP, Taylor LL, Bland V, Jones $\mathrm{P}$, Armstrong D, Gresham ACJ, Hartung J, Chennells DJ and Done SH 2004. Production responses of weaned pigs after chronic exposure to airborne dust and ammonia. Animal Science 78, 87-97. 